\title{
Heterogeneous Requirement of NGF for Sympathetic Target Innervation In Vivo
}

\author{
Natalia 0. Glebova and David D. Ginty \\ Department of Neuroscience, Howard Hughes Medical Institute, The Johns Hopkins University School of Medicine, Baltimore, Maryland 21205
}

The neurotrophin nerve growth factor (NGF) plays a crucial role in the development of the sympathetic nervous system. In addition to being required for sympathetic neuron survival in vivo and in vitro, NGF has been shown to mediate axon growth in vitro. The role of NGF in sympathetic axon growth in vivo, however, is not clear because of its requirement for survival. This requirement can be circumvented by a concomitant deletion of $\mathrm{Bax}$, a pro-apoptotic Bcl-2 family member, thus allowing an examination of the role of neurotrophins in axon growth independently of their function in cell survival. Here, we analyzed peripheral sympathetic target organ innervation in mice deficient for both $N G F$ and $B a x$. In neonatal $N G F^{-1-} ; B a x^{-1-}$ mice, sympathetic target innervation was absent in certain organs (such as salivary glands), greatly reduced in others (such as heart), somewhat diminished in a few (such as stomach and kidneys), but not significantly different from control in some (such as trachea). At embryonic day 16.5, peripheral target sympathetic innervation was also reduced in $\mathrm{NGF}^{-I-}$; $\mathrm{Bax}^{-1-}$ mice, with analogous variability for different organs. Interestingly, in some organs such as the spleen the precise location at which sympathetic axons become NGF-dependent for growth was evident. We thus show that NGF is required for complete peripheral innervation of both paravertebral and prevertebral sympathetic ganglia targets in vivo independently of its requirement for cell survival. Remarkably, target organs vary widely in their individual NGF requirements for sympathetic innervation.

Key words: NGF; TrkA; Bax; sympathetic neuron; axon growth; development

\section{Introduction}

The development of the peripheral nervous system is a remarkable feat of intricate coordination between the progressive maturation of innervated organs and the corresponding growth of axons. The staggering complexity of a growing mammalian embryo presents a challenge to the multitude of neurons that come to innervate their targets. To achieve precise functional organization, peripheral targets regulate neuron survival in accordance with the neurotrophin hypothesis, which specifies that neuronal survival during development is dependent on a limited supply of trophic factors produced by the neuron's target (Huang and Reichardt, 2001; Bennet et al., 2002). Such neurotrophic factors act to ensure that neuron numbers precisely match target innervation requirements.

The classical neurotrophin nerve growth factor (NGF) plays a crucial role in the development of the peripheral nervous system (Levi-Montalcini, 1987; Cowan, 2001; Sofroniew et al., 2001), being essential for survival of small nociceptive sensory neurons as well as sympathetic neurons (Farinas, 1999). The importance of NGF in the development of sympathetic neurons is clear, as is evident from the dramatic loss of these neurons in mice either

Received 0ct. 4, 2003; revised Nov. 29, 2003; accepted Nov. 29, 2003.

This work was supported by the Medical Scientist Training Program, National Institutes of Health Grant R01NS34814, and the Howard Hughes Medical Institute. We thank Bonnie Lonze for technical guidance and discussion, Dr. Lawrence Schramm and members of the Ginty laboratory for discussion of this manuscript, Dr. William Snider for providing $\mathrm{Bax}^{+/-}$mice, and Taeho Kim for assistance with early stages of mouse husbandry.

Correspondence should be addressed to Dr. David Ginty, Department of Neuroscience, The Howard Hughes Medical Institute, Johns Hopkins University School of Medicine, Baltimore, MD 21205. E-mail: dginty@jhmi.edu. DOI:10.1523/JNEUROSCI.4523-03.2004

Copyright $\odot 2004$ Society for Neuroscience $\quad 0270-6474 / 04 / 240743-09 \$ 15.00 / 0$ treated with neutralizing NGF antibodies or harboring a targeted deletion of NGF (Levi-Montalcini and Booker, 1960b; Angeletti and Levi-Montalcini, 1971; Crowley et al., 1994).

In addition to its role in sympathetic neuron survival in vivo (Levi-Montalcini and Booker, 1960b; Angeletti and LeviMontalcini, 1971; Crowley et al., 1994) and in vitro (Greene, 1977; Martin et al., 1988; Deshmukh and Johnson, 1997), NGF is a potent growth-promoting factor for axons of sympathetic neurons in vitro (Cohen and Hamburger, 1954; Mains and Patterson, 1973; Deckwerth et al., 1996; Atwal et al., 2000). In vivo gain-offunction experiments have also shown that exogenous NGF can induce sympathetic axon growth (Levi-Montalcini and Booker, 1960a; Albers et al., 1994); however, the critical requirement of NGF for sympathetic neuron survival during development (Crowley et al., 1994) has impeded efforts to establish the extent to which NGF is required for sympathetic axon growth in vivo.

Recently, assessment of neurotrophin roles during neuronal development in vivo has been made possible by the elegant strategy of deleting Bax, a pro-apoptotic Bcl-2 family member (Oltvai et al., 1993), concurrently with removal of a neurotrophin gene (Patel et al., 2000, 2003). Bax ${ }^{-1-}$ mice (Knudson et al., 1995) exhibit a striking deficiency in naturally occurring developmental cell death in the peripheral nervous system, as well as a marked reduction in trophic factor deprivation-induced neuronal apoptosis (Deckwerth et al., 1996; Deshmukh and Johnson, 1998). When $\mathrm{NGF}^{-1-}$; $\mathrm{Bax}^{-1-}$ mice are generated, the excess death of sensory and sympathetic neurons otherwise observed in $\mathrm{NGF}^{-1-}$ mice (Crowley et al., 1994) is prevented (Patel et al., 2000; Middleton and Davies, 2001). This genetic approach thus allows 
an examination of the role of NGF in vivo independently of its requirement for cell survival.

We used this method of concurrent elimination of Bax and NGF to establish the extent to which NGF is required for sympathetic axon growth in vivo. We analyzed the development of peripheral sympathetic target organ innervation in $\mathrm{NGF}^{-1-}$; $\mathrm{Bax}^{-1-}$ mice at embryonic day (E) 16.5 and postnatal day (P) 0.5 by performing whole-mount immunohistochemistry using tyrosine hydroxylase (TH), the rate-limiting enzyme in catecholamine biosynthesis (Flatmark, 2000), as a marker for sympathetic neurons. We found that NGF is required for sympathetic axon growth into peripheral target organs and, remarkably, that the extent of this requirement varies greatly among different target organs. NGF is thus necessary for development of the elaborate labyrinth of axons that characterizes the anatomy of the sympathetic nervous system.

\section{Materials and Methods}

Mouse breeding and genotyping. $\mathrm{NGF}^{+1-}$ mice (Crowley et al., 1994) were obtained from The Jackson Laboratory (Bar Harbor, ME) and maintained on C57BL/6 background. PCR genotyping was done on tail DNA with the following primers: the wild-type NGF allele (500 bp) was amplified using an exon IV forward primer (5'-CAGGCAGAACCGTACACAGA$\left.3^{\prime}\right)$ and an exon IV reverse primer $\left(5^{\prime}\right.$ GCACCCACTCTCAACAGGAT- $3^{\prime}$ ). The mutant NGF allele (1300 bp) was amplified with a Neo forward primer (5'-TGAATGAACTGCAGGACGAG- $3^{\prime}$ ) and the same exon IV reverse primer. Bax ${ }^{+/-}$mice (Knudson et al., 1995) were provided by Dr. William Snider (University of North Carolina, Chapel Hill, NC) and maintained on C57BL/6 background. PCR genotyping was done on tail DNA with the following primers: the wild-type Bax allele ( $350 \mathrm{bp}$ ) was amplified with an exon $\mathrm{V}$ forward primer (5'-CGAGCTGATCAGAACCATCAT- $3^{\prime}$ ) and an intron $\mathrm{V}$ reverse primer (5'-AATCTTTAGGCCAGAGCAAGC-3'). The mutant Bax allele (515 bp) was amplified with a PGK-neo forward primer (5'-ACTTCCATTTGTCACGTCCTG-3') and the same intron V reverse primer. PCR was performed according to standard reaction conditions, with primer concentrations at $1 \mu \mathrm{M}$ and $\mathrm{MgCl}_{2}$ at $1.5 \mathrm{~mm}$. Cycling parameters were $5 \mathrm{~min}$ at $94^{\circ} \mathrm{C} ; 30 \mathrm{sec}$ at $94^{\circ} \mathrm{C}, 30 \mathrm{sec}$ at $58^{\circ} \mathrm{C}, 1.5 \mathrm{~min}$ at $72^{\circ} \mathrm{C}$ for $30 \mathrm{cycles}$; and 10 min at $72^{\circ} \mathrm{C} . \mathrm{NGF}^{+/-}$mice were bred to $\mathrm{Bax}^{+/-}$mice to obtain $\mathrm{NGF}^{+/-}$; $\mathrm{Bax}{ }^{+/-}$mice, which were then crossed to generate $\mathrm{NGF}^{-1-} ; \mathrm{Bax}^{-1-}$ mice and relevant controls.

Whole-mount diaminobenzidine-tyrosine hydroxylase immunohistochemistry. Whole-mount diaminobenzidine (DAB)-TH immunohistochemistry was performed as described previously (Enomoto et al., 2001) with sheep anti-TH affinity-purified polyclonal antibody (Chemicon International, Temecula, CA) at $0.5 \mu \mathrm{g} / \mathrm{ml}$ incubated for $72 \mathrm{hr}$ at $4^{\circ} \mathrm{C}$. Detection was performed with horseradish peroxidase-conjugated donkey anti-sheep IgG (Jackson ImmunoResearch Laboratories, West Grove, PA) at $4 \mu \mathrm{g} / \mathrm{ml}$ incubated overnight at $4^{\circ} \mathrm{C}$. Visualization was accomplished with DAB (Sigma, St. Louis, MO), followed by clearing in 2:1 benzyl benzoate/benzyl alcohol (Sigma). The number of animals examined at E16.5 was as follows: $n=3\left(\mathrm{NGF}^{+/+} ; \mathrm{Bax}^{+/+}\right), 5\left(\mathrm{NGF}^{-/-}\right.$; $\left.\mathrm{Bax}^{+/+}\right), 4\left(\mathrm{NGF}^{+/+} ; \mathrm{Bax}^{-/-}\right), 3\left(\mathrm{NGF}^{-1-} ; \mathrm{Bax}^{-1-}\right)$. The number of
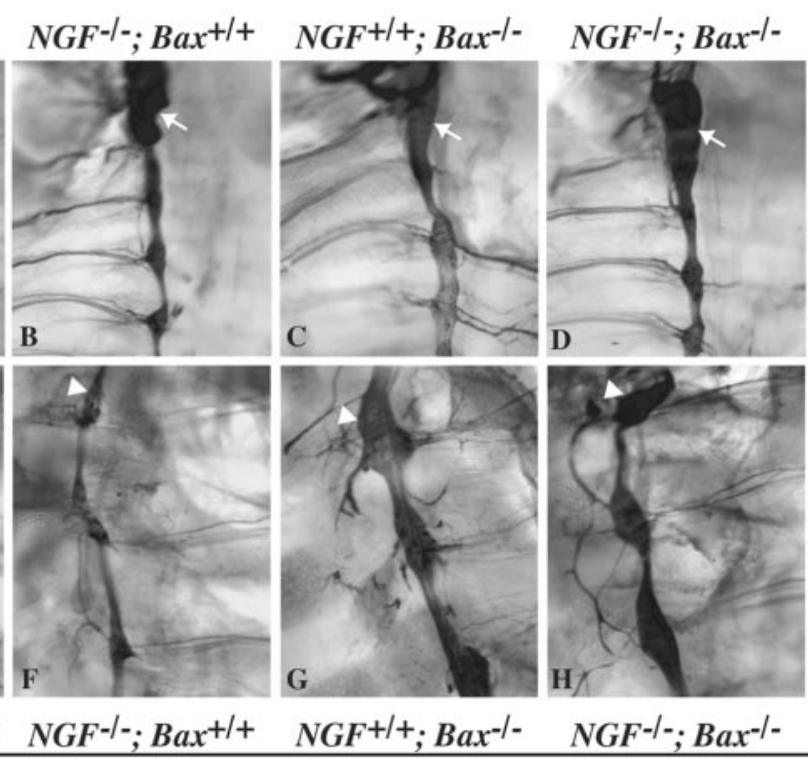

$5,412 \pm 348^{*}$

$44,428 \pm 2025^{* *}$

$45,902 \pm 2279^{* *}$

Figure 1. Elimination of Bax preserves sympathetic chain ganglia neurons in the absence of NGF.A-H, Whole-mount tyrosine hydrox ylase immunostaining of $\mathrm{E} 16.5(A-D)$ and $\mathrm{P} 0.5(E-H)$ sympathetic chain from stellate ganglion (arrows) to T3 chain ganglion $(A-D)$ and demonstrate a clear gross reduction in the size of sympathetic chain ganglia compared with $\mathrm{NGF}^{-1-} ; \mathrm{Bax}^{-1-}$ mice $(H)$, indicating the

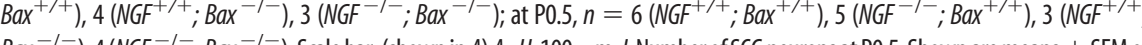
$\left.{ }^{-1-}\right), 4\left(\mathrm{NGF}^{-1-} ; \mathrm{Bax}^{-1-}\right)$. Scale bar: (shown in $\left.A\right) A-H, 100 \mu \mathrm{m}$. I, Number of SCG neurons at P0.5. Shown are means \pm SEM of neuronal counts in three animals for each genotype. ${ }^{*} p<0.0001$ (Significantly different from all other groups); ${ }^{* *}$ indicates not statistically different from one another, as determined using one-way ANOVA followed by Bonferroni/Dunn post hoc test.

animals examined at P0.5 was as follows: $n=6\left(\mathrm{NGF}^{+/+} ; \mathrm{Bax}^{+/+}\right), 5$ $\left(\mathrm{NGF}^{-/-} ; \mathrm{Bax}^{+/+}\right), 3\left(\mathrm{NGF}^{+/+} ; \mathrm{Bax}^{-/-}\right), 4\left(\mathrm{NGF}^{-/-} ; \mathrm{Bax}^{-/-}\right)$.

Neuronal counts. Tissues were immersion fixed in PBS containing 4\% paraformaldehyde, cryoprotected overnight in PBS containing 30\% sucrose, and frozen. Cryostat sections $(10 \mu \mathrm{m})$ were cut and stained with $0.5 \%$ cresyl violet, and cells with visible nucleoli were counted as neurons (Lonze et al., 2002). Statistical analysis was performed using one-way ANOVA followed by Bonferroni/Dunn post hoc text (StatView 4.5).

\section{Results}

Sympathetic chain ganglia are preserved in the absence of NGF with concomitant elimination of $B a x$

$\mathrm{NGF}$ is required for sympathetic neuron survival in vivo, as is evident from the excessive apoptosis and virtually complete elimination of superior cervical ganglion (SCG) neurons in $N G F^{-1-}$ mice beginning at E17.5 and continuing perinatally (Crowley et al., 1994; Farinas, 1999). This essential function of NGF in sympathetic nervous system development is confirmed during gross examination of sympathetic chain ganglia in $\mathrm{NGF}^{-/-}$; $\mathrm{Bax}^{+/+}$ mice at P0.5 as compared with wild-type controls by wholemount TH immunostaining (Fig. 1, compare $F, E$ ). The size of sympathetic chain ganglia is diminished in the absence of NGF postnatally (Fig. $1 F$ ), an observation consistent with previous examination of SCG volume (Crowley et al., 1994). At E16.5, however, no obvious difference is evident between NGF knockout and wild-type chain ganglia as expected (Fig. 1, compare $A$, 
$B$ ), because excessive cell death in the absence of NGF signaling in the SCG commences at E17.5 (Fagan et al., 1996).

To circumvent the requirement of NGF for sympathetic neuron survival, we concomitantly removed Bax and NGF in vivo by intercrossing $\mathrm{NGF}^{+/-}$; Bax ${ }^{+/-}$mice. Removal of Bax rescued neurons in sympathetic chain ganglia from excess cell death otherwise observed in the absence of $N G F$ (Fig. 1, compare $F, H$ ), as well as resulted in an increase in size of sympathetic chain ganglia compared with wild type at P0.5 (Fig. 1, compare E, G). Neuronal cell counts in the SCG confirmed the gross observation that Bax deletion rescues cell death in this paravertebral ganglion (Fig. 1I). This is consistent with previous reports that total SCG neuron numbers are comparable in $\mathrm{NGF}^{+/+} ; \mathrm{Bax}^{-/-}$and $\mathrm{NGF}^{-/-}$; $B a x^{-1-}$ mice (Middleton and Davies, 2001). No gross differences in the size of sympathetic chain ganglia were evident at E16.5 (Fig. $1 A-D$ ) as expected, because Bax deletion-induced rescue of sympathetic neurons from apoptosis is not expected to have any effect before the start of excess sympathetic neuron death at E17.5 (Fagan et al., 1996). We thus confirm that elimination of Bax leads to preservation of sympathetic neurons in $\mathrm{NGF}^{-1-}$ mice.

\section{Proximal projections of the SCG are preserved, but target innervation is deficient in the absence of NGF with concomitant elimination of $\mathrm{Bax}$}

Survival of sympathetic neurons in $\mathrm{NGF}^{-1-}$; $\mathrm{Bax}^{-1-}$ mice allowed us to examine the role of NGF in sympathetic axon growth in vivo. Proximal projections of the SCG, although somewhat stunted, were present in the absence of NGF at E16.5, as is evident in the comparison between $N G F^{-/-}$and $N G F^{+/+}$mice in the $B a x^{-1-}$ background (Fig. 2, compare $A, B$ ). Similarly, proximal projections of the stellate and sympathetic chain ganglia were grossly intact in $\mathrm{NGF}^{-1-} ; \mathrm{Bax}^{-1-}$ mice as compared with $\mathrm{NGF}^{+/+}$; $\mathrm{Bax}^{-/-}$controls at both E16.5 and P0.5 (Fig. 1). Deletion of Bax did not significantly influence the appearance of proximal SCG projections either in the presence or in the absence of $N G F$ (data not shown). However, peripheral sympathetic innervation of an SCG target, the submaxillary salivary gland, was completely absent on elimination of NGF, even with the concurrent rescue of sympathetic neurons from apoptosis by removal of Bax (Fig. 2C-F). Sympathetic axons were found to travel along blood vessels to innervate the submaxillary gland and ramify in the gland parenchyma in $\mathrm{NGF}^{+/+}$; $\mathrm{Bax}^{-/-}$mice at both E16.5 and P0.5 (Fig. 2C,E), but no axons reached the submaxillary gland along blood vessels or entered the gland in $\mathrm{NGF}^{-1-}$; $\mathrm{Bax}^{-1-}$ mice (Fig. $2 D, F$ ). These findings are consistent with a previous study of mice lacking the NGF receptor TrkA, which revealed that sympathetic axons extended from the SCG but failed to innervate the submaxillary gland at E15.5, a time point before commencement of excess cell death in the absence of NGF (Fagan et al., 1996). Similar deficiencies were evident in sympathetic innervation of another SCG target, the parotid salivary gland (data not shown) (Table 1), as well as in cutaneous sympathetic innervation of the eye, also supplied by the SCG (Fig. $2 G, H)$. NGF is thus not required for initial axon outgrowth from the SCG but is necessary for development of sympathetic innervation of SCG target organs in vivo.

\section{Sympathetic innervation of a stellate ganglion target, the heart, is drastically reduced in the absence of NGF with concomitant elimination of $B a x$}

NGF was found to be necessary for peripheral sympathetic innervation not only of SCG target organs but also of organs that are innervated by neurons originating from other sympathetic gan-
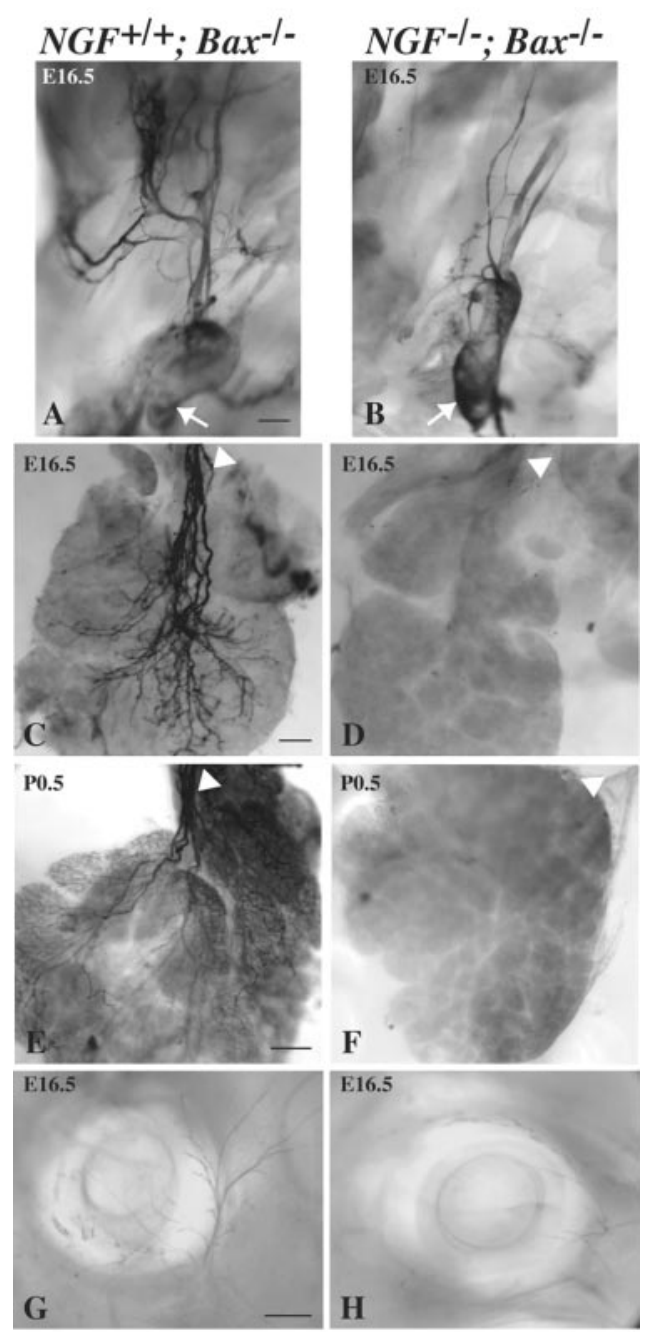

Figure 2. SCG neurons extend proximal axonal projections but fail to innervate their target organs in $\mathrm{NGF}^{-1-} ; \mathrm{Bax}^{-1-}$ mice. $A, B$, Whole-mount tyrosine hydroxylase immunostaining of E16.5 SCG (arrows) and its proximal projections demonstrates that SCG neurons extend proximal projections in $\mathrm{NGF}^{-1-}$; $\mathrm{Bax}^{-1-}$ mice $(B)$ as compared with $\mathrm{NGF}^{+/+} ; \mathrm{Bax}^{-1-}$ controls (A). $C-F$, Whole-mount tyrosine hydroxylase immunostaining of submaxillary salivary gland indicates that sympathetic neuron projections along blood vessels entering the gland (arrowheads) and innervation of the parenchyma are absent in $\mathrm{NGF}^{-1-} ; \mathrm{Bax}^{-1-}$ mice $(D, F)$ as compared with $\mathrm{NGF}^{+/+} ; \mathrm{Bax}^{-1-}$ controls $(C, E)$ at both $\mathrm{E} 16.5(C, D)$ and P0.5 $(E, F) . G, H$, Whole-mount tyrosine hydroxylase immunostaining of cutaneous sympathetic innervation of the eye at E16.5 indicates that SCG neurons fail to innervate this target in $\mathrm{NGF}^{-1-}$; $\mathrm{Bax}^{-1-}$ mice $(H)$ as compared with control $N G F^{+/+} ; \mathrm{Bax}^{-I-}$ animals $(G)$. Scale bars: $A-D, 100 \mu \mathrm{m} ; E-H, 250 \mu \mathrm{m}$.

glia. Sympathetic innervation of the heart in rodents is provided primarily by the stellate ganglion, with minor contributions from the SCG and mid-thoracic paravertebral ganglia (Pardini et al., 1989). In the absence of NGF, sympathetic innervation of the heart was reduced drastically, with few fibers visible at the base in $N G F^{-1-}$; $\mathrm{Bax}^{-1-}$ mice (Fig. $3 \mathrm{~B}, \mathrm{D}$ ) as compared with $\mathrm{NGF}^{+/+}$; $\mathrm{Bax}^{-/-}$controls (Fig. $3 A, C$ ), which were not significantly different from wild type (data not shown). The paucity of sympathetic fibers innervating the heart was evident at both E16.5 (Fig. $3 A, B$ ) and P0.5 (Fig. 3C,D), suggesting that the lack of sympathetic axons at the later age was not the result of deficient maintenance of innervation but instead was caused by a primary failure in axon extension into the heart. Sympathetic innervation of another stellate ganglion target, the lungs (Kummer et al., 1992), was also reduced (data not shown) (Table 1 ). 


\section{Requirement of NGF for peripheral innervation of SCG and} stellate ganglia targets is variable depending on the organ

NGF was thus found to be required for sympathetic innervation of both SCG and stellate ganglion targets, including the salivary glands and heart, respectively. This requirement for NGF was not uniform, however, as is evident in the case of sympathetic innervation of the trachea. The trachea in rodents receives the majority of its sympathetic innervation from the SCG and the remainder from the stellate ganglion (Smith and Satchell, 1985, 1986; Kummer et al., 1992). Surprisingly, the trachea in $\mathrm{NGF}^{-1-} ; \mathrm{Bax}^{-1-}$ mice (Fig. $3 F, H$ ) did not exhibit such striking defects in gross sympathetic innervation in comparison with $\mathrm{NGF}^{+/+}$; $\mathrm{Bax}{ }^{-/-}$ controls (Fig. $3 E, G$ ) as did the salivary glands and the heart. The trachea was clearly sympathetically innervated at E16.5 in the absence of NGF (Fig. $3 F$ ) as compared with control (Fig. $3 E$ ), albeit to a lesser extent. Moreover, at P0.5, a difference in the level of sympathetic innervation of the trachea was not evident, although innervation appeared disorganized (Fig. 3G,H). Different peripheral targets of the same sympathetic ganglia thus exhibit distinct requirements for NGF for sympathetic innervation, as is evident in the heterogeneous deficits in sympathetic innervation of the trachea, heart, and salivary glands in $\mathrm{NGF}^{-1-}$; $\mathrm{Bax}^{-1-}$ mice.

Target organs of prevertebral sympathetic ganglia are incompletely innervated by sympathetic axons in the absence of NGF with concomitant elimination of $B a x$

The superior cervical and stellate ganglia, the target organs of which are described above, constitute part of the sympathetic trunk, which also includes thoracic and lumbar paravertebral sympathetic ganglia. In addition to the chain paravertebral ganglia, the sympathetic nervous system contains prevertebral ganglia, such as the celiac and mesenteric ganglia, which innervate target organs in the abdomen, pelvis, and perineum [for a diagram of rodent sympathetic ganglia organization, see Roosen et al. (2001)]. The celiac ganglion, for example, provides the majority of sympathetic innervation of the rodent stomach, which also receives a minor contribution from all thoracic chain paravertebral ganglia (Trudrung et al., 1994). NGF was found to be required for peripheral innervation of this celiac ganglion target: sympathetic innervation of the body of the stomach was diminished in $\mathrm{NGF}^{-1-}$; $B a x^{-1-}$ mice (Fig. $4 D, H$ ) as compared with $\mathrm{NGF}^{+/+}$; $\mathrm{Bax}^{-/-}$controls (Fig. $4 C, G$ ) at both E16.5 (Fig. 4C,D) and P0.5

(Fig. 4G,H). This reduction in sympa-

thetic innervation, however, was not nearly as dramatic as that seen in the submaxillary gland and heart (Figs. $2 C-F, 3 A-D$ ), as is evident from the presence of a considerable amount of sympathetic fibers in the cardiac region of the stomach in the absence of $N G F$ (Fig. 4, compare $A, B$ and $E, F$ ). NGF is thus required for complete innervation of the stomach but is not necessary for the initial extension of sympathetic axons into the stomach. This is in contrast to the phenotype observed in the heart and salivary glands, which require NGF for development of any sympathetic innervation.

\begin{tabular}{llc}
$\begin{array}{l}\text { Table 1. Sympathetic innervation in } \text { NGF }^{-/-} ; \text {Bax }^{-/-} \text {mice relative to } \text { NGF }^{+/+} ; \\
\text {Bax controls }\end{array}$ & E16.5 & \\
\hline Organ & +++ & P0.5 \\
\hline Sympathetic chain & +++ & +++ \\
Intercostal nerves $^{a}$ & ++ & +++ \\
Carotid arteries $^{b}$ & - & $\mathrm{NE}$ \\
Submaxillary gland $^{-1}$ & - & - \\
Parotid gland & + & $\mathrm{NE}$ \\
Skin, cephalic & - & - \\
Heart, ventricle & + & + \\
Heart, base & + & + \\
Thymus & + & + \\
Lung & ++ & +++ \\
Trachea & ++ & ++ \\
Stomach & ++ & ++ \\
Small intestine & + & + \\
Large intestine & + & + \\
Liver & + & + \\
Spleen & + & + \\
Pancreas & ++ & ++ \\
Kidney & + & + \\
Ureter & ++ & ++ \\
Bladder & ++ & ++ \\
Gonads & & +
\end{tabular}

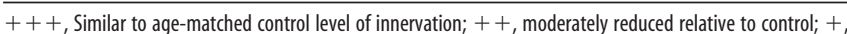
greatly reduced relative to control; - , absent relative to control. NE, Not examined.

${ }^{a}$ Proximal projections of sympathetic chain ganglia.

${ }^{b}$ Proximal projections of the SCG.

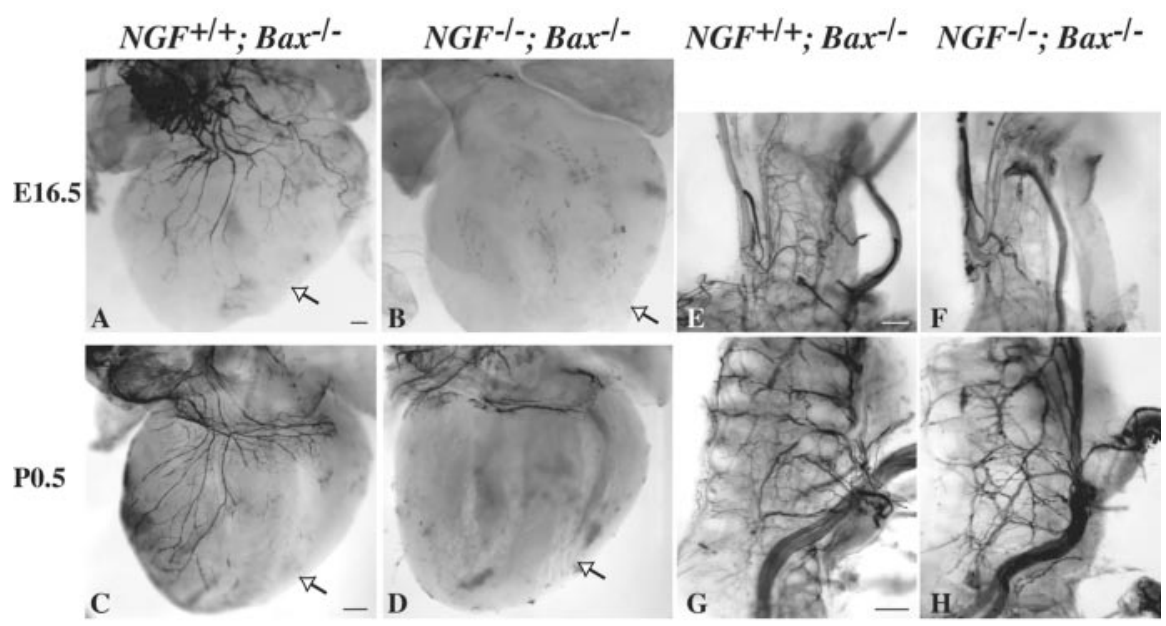

Figure 3. Sympathetic innervation of the heart is deficient but that of the trachea is maintained in $\mathrm{NGF}^{-1-} ; \mathrm{Bax}^{-1-}$ mice. $A-D$, Whole-mount tyrosine hydroxylase immunostaining of heart ventricles (arrows) shows the lack of sympathetic innervation in $\mathrm{NGF}^{-1-} ; \mathrm{Bax}^{-1-}$ mice $(B, D)$ as compared with $\mathrm{NGF}^{+/+} ; \mathrm{Bax}^{-1-}$ controls $(A, C$ at both $\mathrm{E} 16.5(A, B)$ and P0.5 (C, D). E-H, Whole-mount tyrosine hydroxylase immunostaining of dorsal trachea reveals a slight reduction in its sympathetic innervation at $\mathrm{E} 16.5(E, F)$ but no significant gross differences in the level of its sympathetic innervation at $\mathrm{P0} 0.5(G, H)$ in $\mathrm{NGF}^{-1-} ; \mathrm{Bax}^{-1-}$ mice $(F, H)$ as compared with $N G F^{+/+} ; B a x^{-/-}$controls $(E, G)$. Scale bars: $A, B, E, F, 100 \mu \mathrm{m} ; C, D, G, H, 250 \mu \mathrm{m}$.
Another organ innervated by the celiac ganglion is the kidney. In contrast to the stomach, however, the rodent kidney receives the majority of its sympathetic innervation from paravertebral ganglia (T10-L1) and a minority from the celiac ganglion (Ferguson et al., 1986; Gattone et al., 1986; Chevendra and Weaver, 1991; Dehal et al., 1993). Despite this difference in ganglionic origins of sympathetic innervation, the kidney exhibits a similar NGF requirement for complete sympathetic innervation. Although the stereotypical major sympathetic neuron projections along blood vessels in the kidney are present in $\mathrm{NGF}^{-1-} ; \mathrm{Bax}^{-1-}$ 

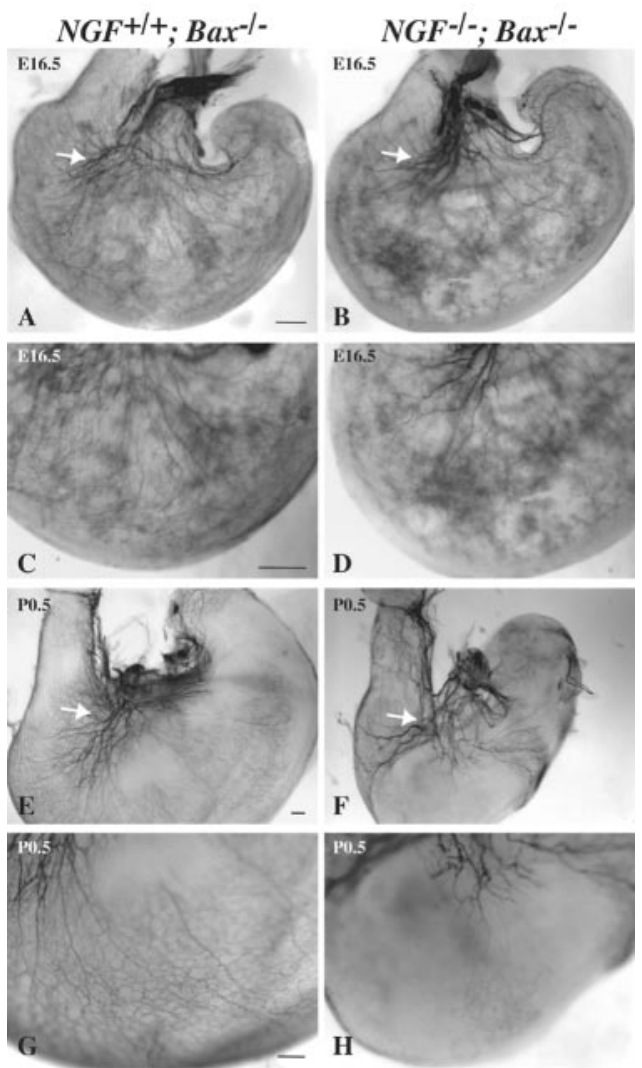

Figure 4. NGF is required for complete sympathetic innervation of the stomach. A-H, Whole-mount tyrosine hydroxylase immunostaining of body of the stomach demonstrates deficient sympathetic innervation in $\mathrm{NGF}^{-1-} ; \mathrm{Bax}^{-1-}$ mice $(D, H)$ as compared with $\mathrm{NGF}^{+/+}$; $B a x^{-I-}$ controls $(C, G)$ at both E16.5 (C, D) and P0.5 $(G, H)$. Lower magnification photographs illustrate presence of sympathetic innervation in the cardiac region of the stomach (arrows) for all genotypes at E16.5 $(A, B)$ and P0.5 $(E, F)$. Although shown at the same magnification, $\mathrm{NGF}^{+/+} ; \mathrm{Bax}^{-1-}$ stomach at $\mathrm{PO} .5(E)$ appears larger than $\mathrm{NGF}^{-1-} ; \mathrm{Bax}^{-1-}$ stomach at $\mathrm{P} 0.5$ $(F)$ because of distension from milk in control stomach, which is absent in $\mathrm{NGF}^{-1-} ; \mathrm{Bax}^{-1-}$ animals because of deficient feeding behavior in the absence of NGF. Scale bars: $A-D, 100 \mu \mathrm{m}$; $E-H, 250 \mu \mathrm{m}$

mice (Fig. 5A-D), sympathetic axons fail to ramify and fully innervate the kidney parenchyma in $\mathrm{NGF}^{-1-}$; $\mathrm{Bax}^{-1-}$ animals (Fig. $5 B, D$ ) as compared with $\mathrm{NGF}^{+/+}$; $\mathrm{Bax}^{-/-}$controls (Fig. $5 A, C$ ) at both E16.5 (Fig. $5 A, B$ ) and P0.5 (Fig. 5C,D). The dearth of fine sympathetic axon branches in the absence of NGF is evident in the kidneys of $\mathrm{NGF}^{-1-}$; $\mathrm{Bax}^{-1-}$ mice (Fig. $5 \mathrm{~F}$ ) in comparison with $\mathrm{NGF}^{+/+} ; \mathrm{Bax}^{-/-}$controls (Fig. $5 E$ ). These findings indicate that factors other than NGF support axon growth along renal arteries into the kidney, whereas NGF is crucial for branching and extension in renal parenchyma.

In addition to the celiac ganglion targets described above, sympathetic innervation defects attributable to the absence of $N G F$ were evident in other prevertebral ganglia targets. The entire gastrointestinal tract, innervated in rodents by celiac and mesenteric ganglia as well as by lower thoracic paravertebral ganglia (Luckensmeyer and Keast, 1994), showed a reduction in sympathetic innervation in the absence of $N G F$ (Fig. 6, compare $A, B$ ). In the proximal small intestine, which in rodents receives innervation primarily from the celiac and to a lesser extent from lower thoracic ganglia (Trudrung et al., 1994), sympathetic axons extended along the vasculature toward the intestine but failed to fully innervate the organ in $\mathrm{NGF}^{-1-} ; \mathrm{Bax}^{-1-}$ mice at both E16.5 and P0.5 (Fig. $6 D, F$ ) as compared with $\mathrm{NGF}^{+/+}$; $\mathrm{Bax}^{-1-}$ con-

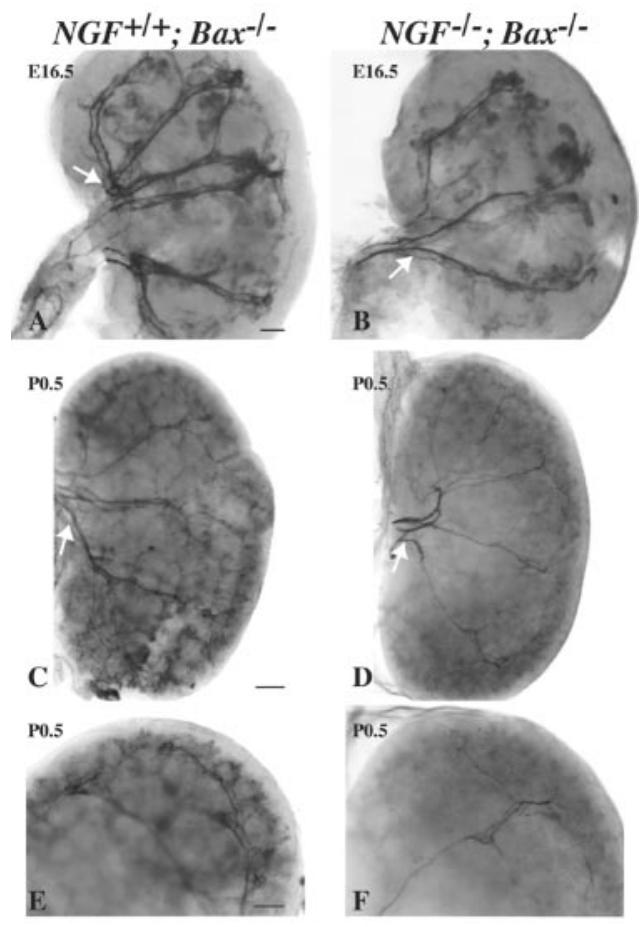

Figure 5. The kidney is incompletely innervated by sympathetic neurons in $N G F^{-1-}$; $\mathrm{Bax}^{-1-}$ mice. $A-F$, Whole-mount tyrosine hydroxylase immunostaining of kidneys reveals the presence of sympathetic axon extension along renal arteries $(A-D$, arrows) but deficient innervation of kidney parenchyma $(E, F)$ in $N_{G F}^{-1-} ; B^{-1-}$ mice $(B, D, F)$ as compared with $N_{G F}^{+/+} ; B a x^{-1-}$ controls $(A, C, E)$ at both E16.5 $(A, B)$ and P0.5 (C-F). Scale bars: $A, B, E, F, 100$ $\mu \mathrm{m} ; C, D, 250 \mu \mathrm{m}$.

trols (Fig. 6C,E). The distal large intestine, innervated in rodents by superior and inferior mesenteric ganglia and lumbar paravertebral ganglia (Trudrung et al., 1994), also showed a decrease in, but not a complete absence of, sympathetic innervation in $\mathrm{NGF}^{-1-}$; $\mathrm{Bax}^{-1-}$ animals at both E16.5 and P0.5 (Fig. $6 \mathrm{H}, \mathrm{J}$ ) as compared with $\mathrm{NGF}^{+/+}$; $\mathrm{Bax}^{-/-}$controls (Fig. 6G,I). Other targets of the inferior mesenteric ganglion and lumbosacral paravertebral ganglia (Baljet and Drukker, 1980; Vera and Nadelhaft, 1992; Ricker and Chang, 1996) demonstrated deficits in sympathetic innervation in the absence of NGF: the ureters (Fig. 7A-D), bladder (Fig. 7E,F), and gonads (Fig. 7G-J) all exhibited decreased sympathetic innervation in $\mathrm{NGF}^{-1-} ; \mathrm{Bax}^{-1-}$ mice (Fig. $7 \mathrm{~B}, \mathrm{D}, \mathrm{F}, \mathrm{H}, J$ ) as compared with $\mathrm{NGF}^{+/+} ; \mathrm{Bax}^{-/-}$controls (Fig. $7 A, C, E, G, I)$. NGF is thus required for complete sympathetic innervation of both paravertebral and prevertebral ganglia target organs, although to different extents, depending on the target but not on the ganglion of sympathetic neuron origin.

\section{Sympathetic axons extend along the lienal artery but fail to enter spleen parenchyma in the absence of NGF with concomitant elimination of $B a x$}

Another organ innervated by prevertebral ganglion sympathetic neurons is the spleen, which in rodents receives most of its sympathetic innervation from the celiac ganglion, with a minor contribution from the lower thoracic paravertebral sympathetic chain ganglia (Chevendra et al., 1991; Quinson et al., 2001). In contrast to other prevertebral ganglion targets described above, which showed a reduction in sympathetic innervation but not a complete elimination of sympathetic axons in the organs themselves, the spleen displayed a remarkable phenotype. Sympathetic axons were seen traveling along the lienal artery and entering 
spleen parenchyma in $\mathrm{NGF}^{+/+}$; $\mathrm{Bax}^{-/-}$ controls, which were not grossly different from wild-type animals at both E16.5 and P0.5 (Fig. $8 A, C$ ) (data not shown). In $N G F^{-1-} ; \mathrm{Bax}^{-1-}$ mice, however, sympathetic axons extended along the lienal artery but did not enter the spleen at both E16.5 and P0.5 (Fig. 8B,D). This finding suggests that the NGF requirement for sympathetic innervation of the spleen begins at the boundary between the artery and the organ itself.

\section{Discussion}

Discovered and named for its ability to promote the growth of sensory and sympathetic axons $>50$ years ago, NGF has since been shown to play a critical role in survival of several neuronal populations during development (Levi-Montalcini, 1987). Because of this requirement for neuron survival, however, it has not been possible to ascertain whether NGF is necessary for axon growth in vivo. We applied the recently developed approach of evading the excess neuronal apoptosis attributable to elimination of NGF by concomitantly removing Bax (Patel et al., 2000, 2003 ) to perform a comprehensive analysis of sympathetic nervous system development in the absence of NGF, thus providing in vivo evidence for the role of NGF in the development of the sympathetic nervous system. An examination of sympathetic axon extension at E16.5 and P0.5 in $\mathrm{NGF}^{-1-} ; \mathrm{Bax}^{-1-}$ mice has revealed a variable requirement for NGF in peripheral target organ innervation in vivo, one that depends not on the ganglion of origin but rather on the target of the neuron.

Concurrent elimination of Bax in $\mathrm{NGF}^{-1-}$ mice resulted in preservation of sympathetic neurons that otherwise would have undergone apoptosis in the absence of NGF (Fig. 1). These results confirm previous work that demonstrated rescue of SCG neurons from programmed cell death in $\mathrm{NGF}^{-1-} ; \mathrm{Bax}^{-1-}$ mice (Middleton and Davies, 2001). In fact, deletion of Bax has been shown to prevent not just NGF withdrawal-induced sympathetic neuron death, but also apoptosis that occurs naturally during development (Deckwerth et al., 1996). Removal of Bax alone did not affect sympathetic target innervation in vivo, as was evident in a comparison between wild-type $\left(\mathrm{NGF}^{+/+} ; \mathrm{Bax}^{+/+}\right)$and Bax null $\left(\mathrm{NGF}^{+/+} ; \mathrm{Bax}^{-/-}\right)$mice (data not shown). In light of sympathetic neuron rescue in $\mathrm{NGF}^{-1-} ; \mathrm{Bax}^{-1-}$ mice, the observed spectrum of peripheral target organ innervation defects revealed the importance of NGF in sympathetic axon growth.

NGF was not required for proximal projections of SCG (Fig. 2 ), stellate, or paravertebral sympathetic chain ganglia neurons (Fig. 1); however, distal innervation of SCG targets, the eye and the submandibular and parotid salivary glands, was completely lacking in the absence of NGF both embryonically and perinatally (Fig. 2, Table 1) (data not shown). The defects in sympathetic innervation caused by elimination of NGF were not limited to neurons originating in the SCG. The heart and lungs, stellate ganglion targets, also showed drastic decreases in sympathetic
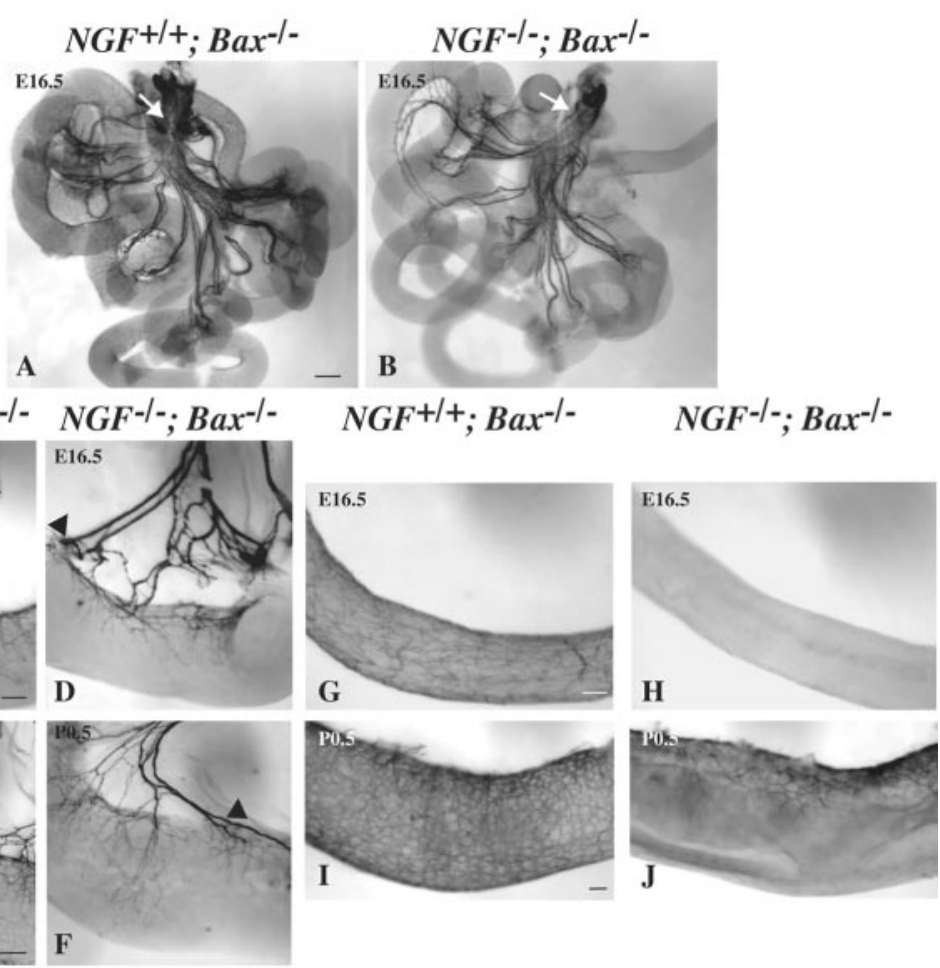

.

Figure 6. Sympathetic innervation of the gastrointestinal tract is deficient in $\mathrm{NGF}^{-1-} ; \mathrm{Bax}^{-1-}$ mice. A-J, Whole-mount tyrosine hydroxylase immunostaining of the entire E16.5 gastrointestinal tract shows that mesenteric sympathetic axon projections (arrows) are present but diminished in $N G F^{-1-} ; B_{a x}{ }^{-1-}$ mice $(B)$ as compared with $N F^{+/+} ; B^{-1-} \operatorname{controls}(A)$. Closer ins roximal small intestine $(C-F)$ demonstrates that sympathetic axons extend along the vasculature toward the small intestine (arrowheads) but do not fully innervate the organ in $N G F^{-1-} ; B_{a x}{ }^{-1-}$ mice $(D, F)$ as compared with $N G F^{+/+}$; Bax $^{-I-}$ controls $(C, E)$ at both $\mathrm{E} 16.5(C, D)$ and P0.5 $(E, F)$. The distal large intestine $(G-J)$ also shows a reduction in sympathetic fiber density in $N G F^{-I-} ; B a x^{-I-}$ mice $(H, J)$ as compared with $N G F^{+/+} ; B_{a x}{ }^{-I-}$ controls $(G, I)$ at both E16.5 $(G, H)$ and P0.5 $(I, J)$. Scale bars: $A, B, E, F, I, J, 250 \mu \mathrm{m} ; C, D, G, H, 100 \mu \mathrm{m}$.

innervation at E16.5 and P0.5 (Fig. 3A-D, Table 1) (data not shown).

Although the SCG and stellate ganglion targets cited above demonstrated a massive reduction in sympathetic innervation in $\mathrm{NGF}^{-1-} ; \mathrm{Bax}^{-1-}$ mice, a target organ innervated by both of these ganglia, the trachea, did not exhibit a notable defect in the level of sympathetic innervation (Fig. $3 E-H$ ). Different paravertebral ganglia targets thus varied in their requirements for NGF for sympathetic axon growth into the organ. Interestingly, some aspects of postganglionic sympathetic neuron heterogeneity, including soma size, dendritic arborization, and age-related atrophy, have been noted to be a function of the innervated target and not of the ganglion of origin (Voyvodic, 1989; Luebke and Wright, 1992; Andrews et al., 1996). Taken together, these findings suggest that the various targets of paravertebral sympathetic neurons differ in their expression and release of distinct trophic substances that mediate sympathetic axon growth into the targets.

In addition to paravertebral ganglia targets, we examined target organs of prevertebral ganglia for the extent of sympathetic innervation in the absence of NGF. The stomach, spleen, pancreas, small and large intestines, kidneys, ureters, bladder, and gonads all demonstrated deficiencies in sympathetic innervation, specifically a reduction in terminal branching of sympathetic neurons but not a complete absence of innervation (Figs. 4-8, Table 1) (data not shown). A pattern thus emerges from these findings wherein most paravertebral ganglia targets exhibit 

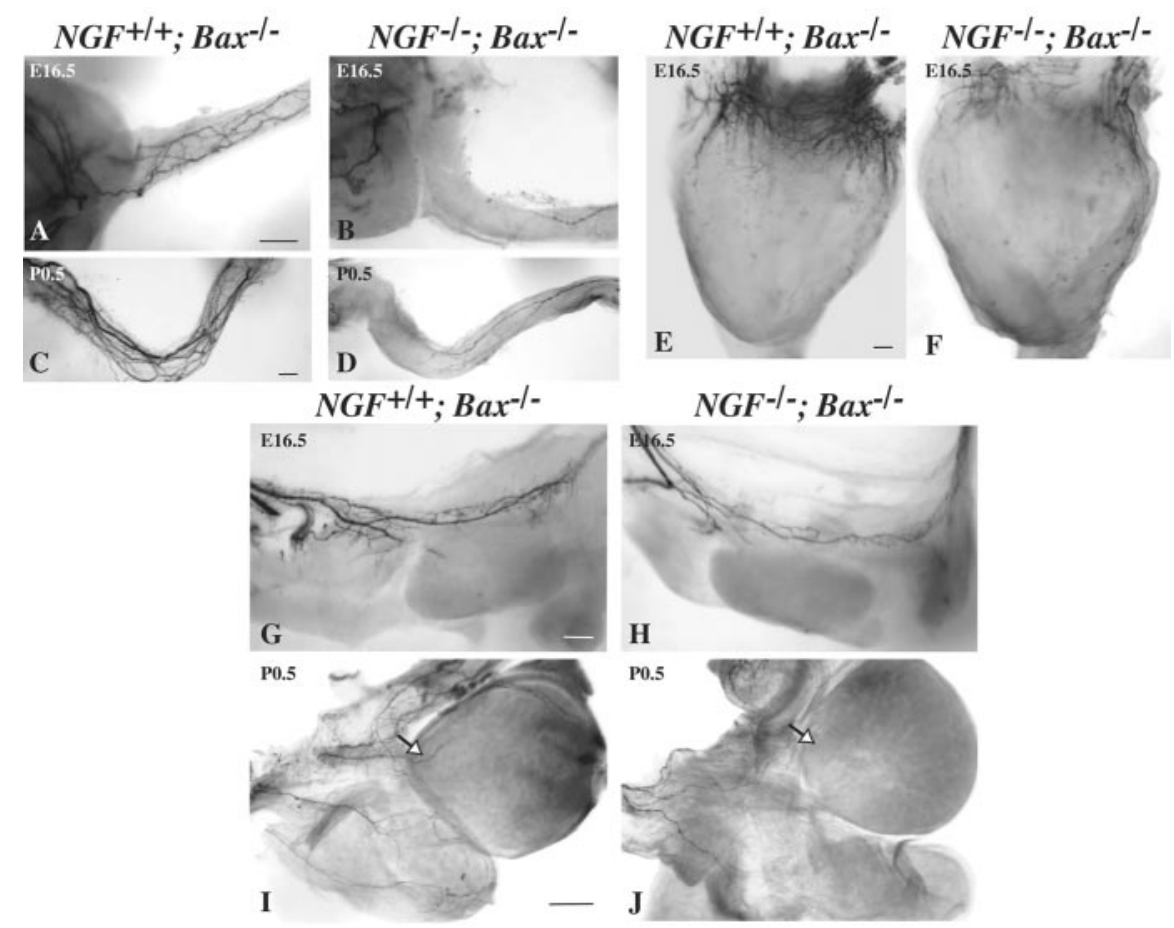

Figure 7. NGF is required for complete sympathetic innervation of ureters, bladder, and gonads. $A-D$, Whole-mount tyrosine hydroxylase immunostaining of proximal ureters reveals a deficit in sympathetic innervation in $\mathrm{NGF}^{-1-} ; B a x^{-1-}$ mice $(B, D)$ as compared with $\mathrm{NGF}^{+/+}$; $\mathrm{Bax}^{-l-}$ controls $(A, C)$ at both E16.5 $(A, B)$ and P0.5 (C, D). E, F, Whole-mount tyrosine hydroxylase immunostaining of $\mathrm{E} 16.5$ bladder shows a reduction in sympathetic innervation in $\mathrm{NGF}^{-1-} ; \mathrm{Bax}{ }^{-1-}$ mice $(F)$ as compared with $\mathrm{NGF}^{+/+} ; \mathrm{Bax}^{-1-}$ controls $(E) . \mathrm{G}-J$, Whole-mount tyrosine hydroxylase immunostaining of gonads demonstrates a deficiency in sympathetic innervation in $\mathrm{NGF}^{-/-} ; \mathrm{Bax}^{-/-}$mice $(H, J)$ as compared with $\mathrm{NGF}^{+/+} ; \mathrm{Bax}^{-l-}$ controls $(\mathrm{G}, I)$ at both $\mathrm{E} 6.5(\mathrm{G}, \mathrm{H})$ and P0.5 (I, J). Arrow indicates testis. Scale bars: $A-H, 100 \mu \mathrm{m} ; I, J, 250 \mu \mathrm{m}$.

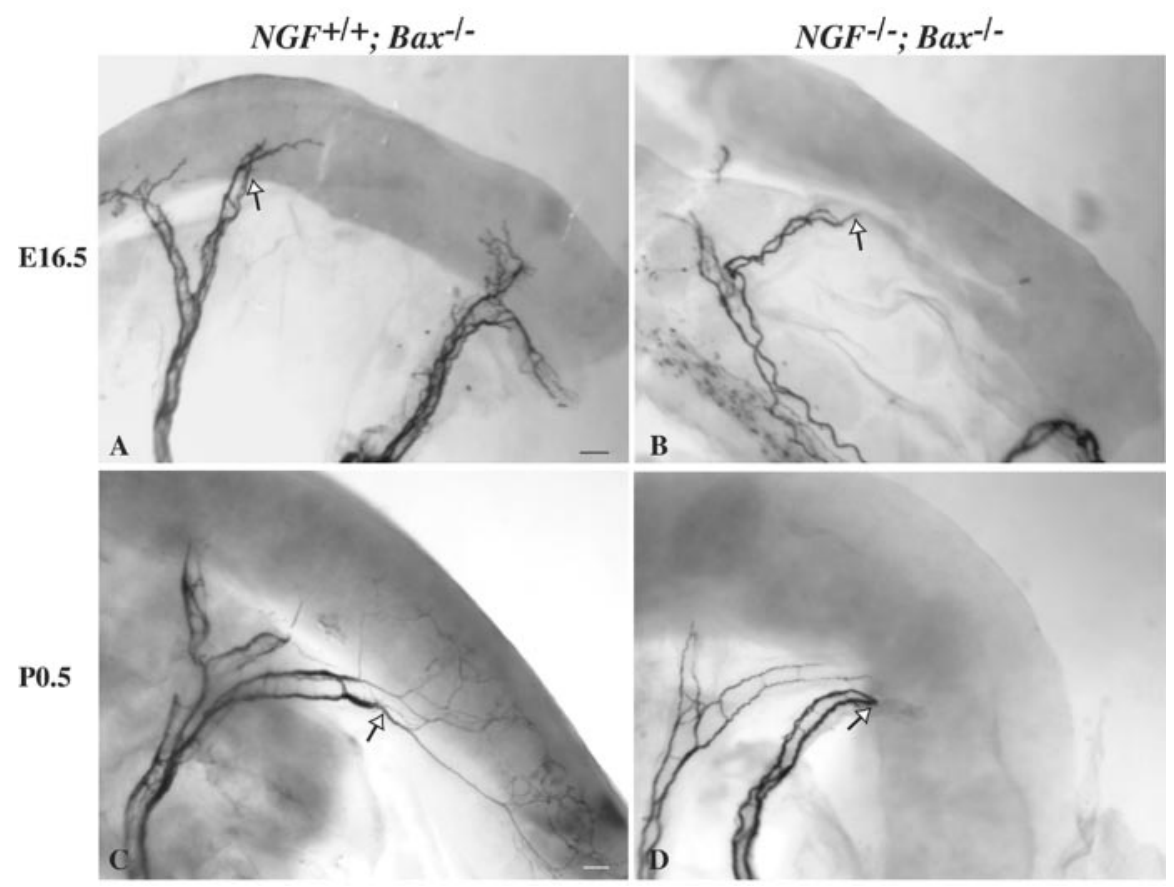

Figure 8. Sympathetic axons extend along the lienal artery but fail to enter spleen parenchyma in $N G F^{-1-} ; B a x^{-1-}$ mice. $A-D$, Whole-mount tyrosine hydroxylase immunostaining of spleen reveals that sympathetic axons arrest at the entrance of the lienal artery into spleen parenchyma (arrow) in $N G F^{-1-} ; B a x^{-1-}$ mice $(B, D)$ as compared with $N G F^{+/+} ; B a x^{-1-}$ controls $(A$, $C$ at both $\mathrm{E} 16.5(A, B)$ and $\mathrm{P} 0.5(C, D)$. Scale bars: $A, B, 50 \mu \mathrm{m} ; C, D, 100 \mu \mathrm{m}$. greater defects in sympathetic innervation in the absence of NGF than do prevertebral ganglia targets (although we cannot distinguish between contributions of prevertebral vs paravertebral ganglia to sympathetic innervation remaining in the absence of NGF in some organs). These results, together with previous findings that prevertebral ganglia neurons are less sensitive than paravertebral ganglia neurons to apoptosis-inducing effects of postnatal injections of anti-NGF (Hill et al., 1985), suggest that prevertebral ganglia targets produce a neurotrophic factor(s) other than NGF and that neurons in these ganglia express molecules that allow them to respond to such cues. In fact, prevertebral (celiac and superior mesenteric) ganglia neurons have been shown to express full-length TrkB mRNA at significantly higher levels than paravertebral (SCG) ganglia neurons (Dixon and McKinnon, 1994). This raises the possibility that the preferred TrkB ligands BDNF and NT-4 may contribute to sympathetic innervation of prevertebral ganglia targets. NT-4, for example, is known to be expressed in one of these targets, the stomach (Berkemeier et al., 1991). Another neurotrophin, NT-3, can also interact with TrkB and thus may also play a role in sympathetic innervation of prevertebral ganglia targets (Ip et al., 1993; Pinon et al., 1996; Farinas et al., 1998).

NT-3 is also a candidate for mediating sympathetic axon growth along the vasculature, an intermediate target en route to the final sympathetic target organs in the periphery. The close relationship between sympathetic axons and arterial vasculature (Enomoto et al., 2001; Honma et al., 2002; Carmeliet, 2003) was evident in all organs examined, and NGF was not required for sympathetic axon extension along arteries approaching target organs (Figs. 2, 5, 6) (data not shown). Furthermore, in the spleen the NGF requirement was seen to commence at the point where sympathetic axons normally leave the lienal artery to innervate spleen parenchyma (Fig. 8). Thus, molecules other than NGF must be responsible for the intact sympathetic axon projections along vasculature in the absence of NGF. NT-3, for example, is expressed in blood vessels (Francis et al., 1999), and NT-3 null mice demonstrate a $50 \%$ decrease in SCG neuron number (Ernfors et al., 1994; Farinas et al., 1994). It is possible that sympathetic neuron loss in NT-3 null mice is caused by deficient axon extension along an intermediate target, the vasculature, which results in an inability of sympathetic neurons to innervate periph- 
eral targets and thus obtain the necessary target-derived survival factors.

Another molecule that may be responsible for the preservation of sympathetic axon extension along the vasculature in the absence of NGF is artemin, a glial cell line-derived neurotrophic factor family member. Mice null for the artemin receptor subunit Ret show deficits in sympathetic neuron precursor migration and axon outgrowth, and exogenous artemin promotes sympathetic axon extension in vivo (Enomoto et al., 2001). Moreover, mice null for either artemin or GFR $\alpha 3$, the preferred artemin receptor, show defects in migration and axonal projections of sympathetic neuroblasts (Honma et al., 2002). Artemin is expressed in arterial smooth muscle cells (Enomoto et al., 2001; Honma et al., 2002) and is thus a plausible candidate for mediating axon growth along vasculature. Additional in vivo studies will be needed to establish the contributions of artemin, NT-3, and other growth factors to extension of proximal projections of both paravertebral and prevertebral sympathetic neurons, as well as to axon growth along blood vessels. These future studies will provide insight not only into the molecular control of axon growth and formation of the sympathetic nervous system, but also the development of neurovascular congruency.

The preservation of sympathetic axons traveling along arteries and the heterogeneity in NGF requirements for full innervation of different sympathetic neuron targets (Table 1) are in contrast with the role of NGF in the growth of sensory neurons reported previously by Patel et al. (2000). Although neither our study nor that of Patel et al. (2000) distinguishes between anatomical and functional preservation of sympathetic or sensory innervation attributable to the perinatal lethality of $\mathrm{NGF}^{-/-} ; \mathrm{Bax}^{+/+}$and $N G F^{-1-}$; $B a x^{-1-}$ mice, a comparison between the findings is informative. In the sensory nervous system, superficial cutaneous innervation was absent in hindlimb skin, a target of dorsal root ganglia sensory neurons, as well as in mystacial pads, a target of the trigeminal ganglion sensory neurons, at E15 and $\mathrm{P} 0$ in $\mathrm{NGF}^{-l-} ; \mathrm{Bax}^{-1-}$ and TrkA ${ }^{-1-} ; \mathrm{Bax}^{-1-}$ mice (Patel et al., 2000). In addition to defects in terminal arborization, this study found a loss of axons in the saphenous nerve, implying that cutaneous sensory axons failed to form initial extensions toward the skin. On the other hand, NGF/TrkA signaling was not required for elaboration of spinal collateral branches of dorsal root ganglia axons (Patel et al., 2000). In our study, sympathetic neurons formed initial axon extensions and exhibited heterogeneous defects in peripheral innervation depending on the target in the absence of NGF (Table 1). Thus, although both sensory and sympathetic neurons depend on NGF for survival during development, these two populations of peripheral neurons differ in their NGF requirements for axon growth.

In summary, we find that NGF is crucial for sympathetic axon growth and innervation of most autonomic target organs in vivo. Furthermore, the NGF requirement for sympathetic axon extension is heterogeneous for different target organs, suggesting that other factors in addition to NGF are produced by some targets and are responsible for axon growth into those organs. In addition, our findings suggest that molecules other than NGF are responsible for mediating growth of proximal projections and sympathetic axon extension along the vasculature. NGF thus coordinates with other unidentified factors the extension of proximal and distal neuron projections during establishment of the intricate anatomical maze of axons necessary for proper function of the sympathetic nervous system.

\section{References}

Albers KM, Wright DE, Davis BM (1994) Overexpression of nerve growth factor in epidermis of transgenic mice causes hypertrophy of the peripheral nervous system. J Neurosci 14:1422-1432.

Andrews TJ, Thrasivoulou C, Nesbit W, Cowen T (1996) Target-specific differences in the dendritic morphology and neuropeptide content of neurons in the rat SCG during development and aging. J Comp Neurol 368:33-44.

Angeletti PU, Levi-Montalcini R (1971) Growth regulation of the sympathetic nervous system: immunosympathectomy and chemical sympathectomy. Rev Eur Etud Clin Biol 16:866-874.

Atwal JK, Massie B, Miller FD, Kaplan DR (2000) The TrkB-Shc site signals neuronal survival and local axon growth via MEK and P13-kinase. Neuron 27:265-277.

Baljet B, Drukker J (1980) The extrinsic innervation of the pelvic organs in the female rat. Acta Anat (Basel) 107:241-267.

Bennet MR, Gibson WG, Lemon G (2002) Neuronal cell death, nerve growth factor and neurotrophic models: 50 years on. Auton Neurosci 95:1-23.

Berkemeier LR, Winslow JW, Kaplan DR, Nikolics K, Goeddel DV, Rosenthal A (1991) Neurotrophin-5: a novel neurotrophic factor that activates trk and trkB. Neuron 7:857-866.

Carmeliet P (2003) Blood vessels and nerves: common signals, pathways, and diseases. Nat Rev: Genetics 4:710-720.

Chevendra V, Weaver LC (1991) Distribution of splenic, mesenteric and renal neurons in sympathetic ganglia in rats. J Auton Nerv Syst 33:47-53.

Cohen S, Levi-Montalcini R, Hamburger V (1954) A nerve growthstimulating factor isolated from sarcomas 37 and 180. Proc Natl Acad Sci USA 40:1014-1018.

Cowan WM (2001) Viktor Hamburger and Rita Levi-Montalcini: the path to the discovery of nerve growth factor. Annu Rev Neurosci 24:551-600.

Crowley C, Spencer SD, Nishimura MC, Chen KS, Pitts-Meek S, Armanini MP, Ling LH, MacMahon SB, Shelton DL, Levinson AD, Phillips HS (1994) Mice lacking nerve growth factor display perinatal loss of sensory and sympathetic neurons yet develop basal forebrain cholinergic neurons. Cell 76:1001-1011.

Deckwerth TL, Elliott JL, Knudson CM, Johnson Jr EM, Snider WD, Korsmeyer SJ (1996) BAX is required for neuronal death after trophic factor deprivation and during development. Neuron 17:401-411.

Dehal NS, Dekaban GA, Krassioukov AV, Picard FJ, Weaver LC (1993) Identification of renal sympathetic preganglionic neurons in hamsters using transsynaptic transport of herpes simplex type 1 virus. Neuroscience 56:227-240.

Deshmukh M, Johnson Jr EM (1997) Programmed cell death in neurons: focus on the pathway of nerve growth factor deprivation-induced death of sympathetic neurons. Mol Pharmacol 51:897-906.

Deshmukh M, Johnson Jr EM (1998) Evidence of a novel event during neuronal death: development of competence-to-die in response to cytoplasmic cytochrome $c$. Neuron 21:695-705.

Dixon JE, McKinnon D (1994) Expression of the trk gene family of neurotrophin receptors in prevertebral sympathetic ganglia. Brain Res Dev Brain Res 77:177-182.

Enomoto H, Crawford PA, Gorodinsky A, Heuckeroth RO, Johnson Jr EM, Milbrandt J (2001) RET signaling is essential for migration, axonal growth and axon guidance of developing sympathetic neurons. Development 128:3963-3974.

Ernfors P, Lee KF, Kucera J, Jaenisch R (1994) Lack of neurotrophin-3 leads to deficiencies in the peripheral nervous system and loss of limb proprioceptive afferents. Cell 77:503-512.

Fagan AM, Zhang H, Landis S, Smeyne RJ, Silos-Santiago I, Barbacid M (1996) TrkA, but not TrkC, receptors are essential for survival of sympathetic neurons in vivo. J Neurosci 16:6208-6218.

Farinas I (1999) Neurotrophin actions during the development of the peripheral nervous system. Microsc Res Tech 45:233-242.

Farinas I, Jones KR, Backus C, Wang XY, Reichardt LF (1994) Severe sensory and sympathetic deficits in mice lacking neurotrophin-3. Nature 369:658-661.

Farinas I, Wilkinson GA, Backus C, Reichardt LF, Patapoutian A (1998) Characterization of neurotrophin and Trk receptor functions in developing sensory ganglia: direct NT-3 activation of TrkB neurons in vivo. Neuron 21:325-334. 
Ferguson M, Ryan GB, Bell C (1986) Localization of sympathetic and sensory neurons innervating the rat kidney. J Auton Nerv Syst 16:279-288.

Flatmark T (2000) Catecholamine biosynthesis and physiological regulation in neuroendocrine cells. Acta Physiol Scand 168:1-17.

Francis N, Farinas I, Brennan C, Rivas-Plata K, Backus C, Reichardt L, Landis S (1999) NT-3, like NGF, is required for survival of sympathetic neurons, but not their precursors. Dev Biol 210:411-427.

Gattone II VH, Marfurt CF, Dallie S (1986) Extrinsic innervation of the rat kidney: a retrograde tracing study. Am J Physiol 250:F189-196.

Greene LA (1977) Quantitative in vitro studies on the nerve growth factor (NGF) requirement of neurons. I. Sympathetic neurons. Dev Biol 58:96-105.

Hill CE, Hendry IA, Ngu MC, van Helden DF (1985) Subpopulations of sympathetic neurones differ in their sensitivity to nerve growth factor antiserum. Brain Res 355:121-130.

Honma Y, Araki T, Gianino S, Bruce A, Heuckeroth R, Johnson E, Milbrandt J (2002) Artemin is a vascular-derived neurotropic factor for developing sympathetic neurons. Neuron 35:267-282.

Huang EJ, Reichardt LF (2001) Neurotrophins: roles in neuronal development and function. Annu Rev Neurosci 24:677-736.

Ip NY, Stitt TN, Tapley P, Klein R, Glass DJ, Fandl J, Greene LA, Barbacid M, Yancopoulos GD (1993) Similarities and differences in the way neurotrophins interact with the Trk receptors in neuronal and nonneuronal cells. Neuron 10:137-149.

Knudson CM, Tung KS, Tourtellotte WG, Brown GA, Korsmeyer SJ (1995) Bax-deficient mice with lymphoid hyperplasia and male germ cell death. Science 270:96-99.

Kummer W, Fischer A, Kurkowski R, Heym C (1992) The sensory and sympathetic innervation of guinea-pig lung and trachea as studied by retrograde neuronal tracing and double-labeling immunohistochemistry. Neuroscience 49:715-737.

Levi-Montalcini R (1987) The nerve growth factor 35 years later. Science 237:1154-1162.

Levi-Montalcini R, Booker B (1960a) Excessive growth of the sympathetic ganglia evoked by a protein isolated from mouse salivary glands. Proc Natl Acad Sci USA 46:373-384.

Levi-Montalcini R, Booker B (1960b) Destruction of the sympathetic ganglia in mammals by an antiserum to a nerve-growth protein. Proc Natl Acad Sci USA 46:384-391.

Lonze BE, Riccio A, Cohen S, Ginty DD (2002) Apoptosis, axonal growth defects, and degeneration of peripheral neurons in mice lacking CREB. Neuron 34:371-385.

Luckensmeyer GB, Keast JR (1994) Projections from the prevertebral and major pelvic ganglia to the ileum and large intestine of the male rat. J Auton Nerv Syst 49:247-259.

Luebke JI, Wright LL (1992) Characterization of superior cervical ganglion neurons that project to the submandibular glands, the eyes, and the pineal gland in rats. Brain Res 589:1-14.

Mains RE, Patterson PH (1973) Primary cultures of dissociated sympathetic neurons. I. Establishment of long-term growth in culture and studies of differentiated properties. J Cell Biol 59:329-345.
Martin DP, Schmidt RE, DiStefano PS, Lowry OH, Carter JG, Johnson EM Jr (1988) Inhibitors of protein synthesis and RNA synthesis prevent neuronal death caused by nerve growth factor deprivation. J Cell Biol 106:829-844.

Middleton G, Davies AM (2001) Populations of NGF-dependent neurones differ in their requirement for BAX to undergo apoptosis in the absence of NGF/TrkA signaling in vivo. Development 128:4715-4728.

Oltvai ZN, Milliman CL, Korsmeyer SJ (1993) Bcl-2 heterodimerizes in vivo with a conserved homolog, Bax, that accelerates programmed cell death. Cell 74:609-619.

Pardini BJ, Lund DD, Schmid PG (1989) Organization of the sympathetic postganglionic innervation of the rat heart. J Auton Nerv Syst 28:193-201.

Patel TD, Jackman A, Rice FL, Kucera J, Snider WD (2000) Development of sensory neurons in the absence of NGF/TrkA signaling in vivo. Neuron 25:345-357.

Patel TD, Kramer I, Kucera J, Niederkofler V, Jessell TM, Arber S, Snider WD (2003) Peripheral NT3 signaling is required for ETS protein expression and central patterning of proprioceptive sensory afferents. Neuron 38:403-416.

Pinon LG, Minichiello L, Klein R, Davies AM (1996) Timing of neuronal death in trkA, trkB and trkC mutant embryos reveals developmental changes in sensory neuron dependence on Trk signaling. Development 122:3255-3261.

Quinson N, Robbins HL, Clark MJ, Furness JB (2001) Locations and innervation of cell bodies of sympathetic neurons projecting to the gastrointestinal tract in the rat. Arch Histol Cytol 64:281-294.

Ricker DD, Chang TS (1996) Neuronal input from the inferior mesenteric ganglion (IMG) affects sperm transport within the rat cauda epididymis. Int J Androl 19:371-376.

Roosen A, Schober A, Strelau J, Bottner M, Faulhaber J, Bendner G, McIlwrath SL, Seller H, Ehmke H, Lewin GR, Unsicker K (2001) Lack of neurotrophin-4 causes selective structural and chemical deficits in sympathetic ganglia and their preganglionic innervation. J Neurosci 21:3073-3084.

Smith RV, Satchell DG (1985) Extrinsic pathways of the adrenergic innervation of the guinea-pig trachealis muscle. J Auton Nerv Syst 14:61-73.

Smith RV, Satchell DG (1986) Determination of extrinsic pathways of adrenergic nerves to the guinea-pig trachealis muscle using surgical denervation and organ-bath pharmacology. Agents Actions 19:48-54.

Sofroniew MV, Howe CL, Mobley WC (2001) Nerve growth factor signaling, neuroprotection, and neural repair. Annu Rev Neurosci 24:1217-1281.

Trudrung P, Furness JB, Pompolo S, Messenger JP (1994) Locations and chemistries of sympathetic nerve cells that project to the gastrointestinal tract and spleen. Arch Histol Cytol 57:139-150.

Vera PL, Nadelhaft I (1992) Afferent and sympathetic innervation of the dome and the base of the urinary bladder of the female rat. Brain Res Bull 29:651-658.

Voyvodic JT (1989) Peripheral target regulation of dendritic geometry in the rat superior cervical ganglion. J Neurosci 9:1997-2010. 